\title{
Subject Diary
}

National Cancer Institute

\section{Source}

National Cancer Institute. Subject Diary. NCI Thesaurus. Code C115589.

An instrument used either to capture a subject's condition or symptoms, or to monitor compliance during a clinical trial or disease treatment while away from the clinical site. 